\title{
A scoping review of health-based survey instruments validated in Brunei Darussalam
}

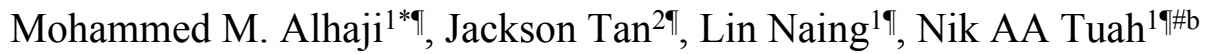

${ }^{1}$ PAPRSB Institute of Health Sciences, Universiti Brunei Darussalam, Bandar Seri Begawan, Brunei Darussalam

${ }^{2}$ RIPAS Hospital, Bandar Seri Begawan, Brunei Darussalam

\#b Primary Care \& Public Health Department, Imperial College London, United Kingdom

*Email: mohalhaj20@yahoo.com.sg

ฯThese authors contributed equally to this work. 


\section{ABSTRACT}

This study sought to map and review validated health-based survey instruments in Brunei Darussalam. A scoping search of relevant articles was carried out. Six health-based survey tools have been psychometrically evaluated in Brunei Darussalam, 4 in Brunei-Malay (SF-36v2, EQ5D/VAS, CPQ ${ }_{11-14}$, and m-SEQ-12) and 2 in English (OFER and WPBA) languages. Two studies (m-SEQ-12, CPQ ${ }_{11-14}$ ) translated tools in English into Brunei-Malay. Two studies (SF-36v2, EQ5D) cross-culturally adapted the Malaysian and Singaporean versions of the tools into BruneiMalay. Four studies were adult- and hospital-based, among healthcare workers (OFER, WPBA) and patients with chronic diseases (SF-36v2, EQ-5D); and 2 studies (m-SEQ-12, CPQ $11-14$ ) were non-adult- and secondary school-based. Pretesting was carried out in 4 studies (SF-36v2, EQ-5D, $\mathrm{CPQ}_{11-14}$, and m-SEQ-12) on a sample of 5 to 20 volunteers. The sample size for validation ranged from 40 to 457. Reliability tests, Cronbach's alpha and intra-class coefficient $(n=3)$, Cohen's Kappa $(n=1)$, and 5-point scale qualitative assessment $(n=1)$ were measured. Validity tests included face validity $(n=2)$, discriminant validity $(n=2)$, convergent validity $(n=2)$, construct validity $(n=2)$, factorial validity $(n=2)$, and 5-point scale qualitative assessment $(n=1)$. There is a need for more psychometric evaluation of questionnaires in Brunei Darussalam. Importantly, large heterogeneous participants, more languages, and varied psychometric tests should be considered.

Keyword: Scoping review; questionnaire design; psychometrics; reliability, validity; SF-36; CPQ, SEQ, WPBA; CPQ; OFER 


\section{Introduction}

The use of standardized and validated questionnaires in health research and clinical practice has gained great prominence over the years [1]. Disease-specific and generic questionnaires are increasingly being used in clinical trials, disease management, and population health monitoring [2]. However, the majority of the health questionnaires have been developed in the English language[3], thus, their applicability in culturally different population or language requires cross-cultural adaptation for lexical, contextual equivalence, and psychometric tests for reliability and validity [4].

The tools translated and adapted for Asian population have shown high psychometric variation from their original versions developed in western population, due to cultural and language peculiarities [5]. Several health-based questionnaires have been translated into the Malaysian Malay which has up to $20 \%$ lexical difference from the Brunei-Malay [6]. However, health researchers in Brunei Darussalam often overlook the important lexical distinction between the two dialects and the potential psychometric dimensional variances that remain unadjusted in adopting Malaysian-Malay health, or self-developed, survey tools with little or no psychometric evaluation [7].

Thus, owing to the ever-increasing application of the scoping review method [8], this review was carried out to map the psychometrically validated health-based survey tools in Brunei Darussalam, and make recommendations for future questionnaire-based studies.

\section{Methods}

\section{Search Strategy}

A broad and systematic search of the literature, using medical subject heading (MeSH) and other relevant search terms, was carried out across PUBMED, MEDLINE and EBSCOhost databases to identify relevant published articles. A search in other databases such as Scopus and Google Scholar, and hand search for relevant grey literature, was also carried out. The search was limited to articles published in English language and no date was specified.

\section{Study Inclusion Criteria}

A study was included if it met all the inclusion criteria: (a) the study is original, (b) it psychometrically evaluated an adapted, or a locally-developed, health-based questionnaire in the Bruneian population, (c) and was published in the English language. The studies which 
psychometrically evaluated questionnaires deemed non-health-based in the Bruneian population were excluded. An health-based questionnaire, in this review, was defined as any tool which measured any concept of health or disease, as defined by the World Health Organization [9].

\section{Studies and data extraction}

One author searched for the articles in the databases, another author scrutinized the retrieved articles for inclusion criteria. The variables of interest were extracted using a modified Systematic Scoping Review protocol, adapted from the standard Joanna Briggs Institute (JBI) Systematic reviews protocol [8]. Overall, information on psychometric evaluation (cultural adaptation, validity and reliability tests), the type of questionnaire, questionnaire item, sample size, sample demographics, and study conclusion were retrieved. The retrieved articles were narratively reviewed, and no statistical procedure was carried out.

\section{Results}

\section{Study Search and Selection}

A total of 401 articles were returned from the database. After the screening of the returned articles, 14 were retained. A further scrutiny of the selected articles against the inclusion criteria resulted in the exclusion of 8 articles. In the end, 6 studies were included in this review (Fig. 1). 
Figure 1: PRISMA Study Search and Selection Flow Diagram [10]

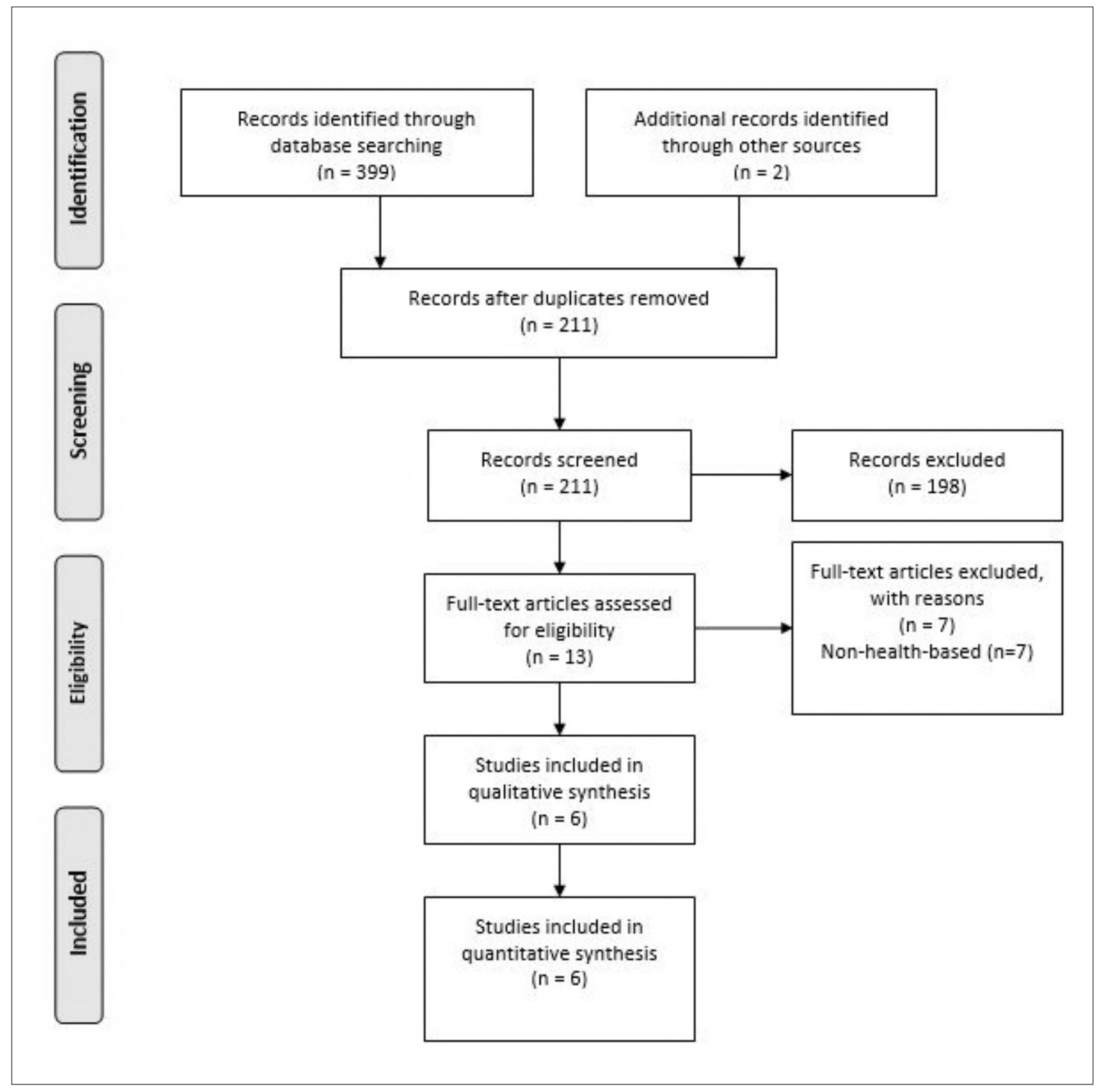




\section{Characteristics of the studies}

The studies $(n=6)$ were all cross-sectional in design, with non-probabilistic samplingconvenient $(n=3)$, purposive $(n=3)$ - being the commonest sampling method. One study used random and convenient sampling methods.[11] Sample size ranged from 40 [12] to 457 [13]. Four studies-Short Form version 2, SF-36v2 [11], EuroQol/Visual Analogue Scale, EQ-5D/VAS [6], Child Perception Questionnaire, $\mathrm{CPQ}_{11-14}$ [13], and modified-Smoking Self-Efficiency Questionnaire, m-SEQ-12 [12]—evaluated tools adapted into Brunei-Malay while 2 studiesOccupational Fatigue Exhaustion Recovery, OFER [14], and Workplace-Based Assessment, WPBA [15] — validated English-based tools. One study was a feedback on postgraduate medical training assessments (WPBA) [15].

Four studies $[6,11,14,15]$ were conducted on adults (18 years old and above), and two studies $[12,13]$ were conducted on children and adolescents (less than 18 years old). Two studies $[12,13]$ were school-based (among high school students), and four studies were hospital-based, among healthcare workers $(n=2)[14,15]$ and patients with chronic disease $(n=2)[6,11]$. One studies had a heterogeneous sample, individuals from the general population and patients with chronic kidney disease [11]. (Table 1)

\section{Psychometric procedure and tests}

Two studies translated the tools in the English language to Brunei-Malay using forward and backward translation method $[12,13]$. Two studies cross-culturally adapted the tools for Bruneian context from the neighbouring Malaysian Malay [6, 11] and Singaporean Malay [6]. Tool pretesting or piloting on a sample size ranging from 5 to 20 was carried out in four studies $[6,11,12,13]$.

On reliability test, internal consistency or homogeneity (Cronbach's alpha) were used in 3 studies $[11,12,13]$; test-retest or stability (intra-class coefficient) in 3 studies $[6,12,13]$, Kohen's Kappa in one study [6], and 5-point scale qualitative feedback in one study [15]. A wide variety of validity tests were used. Face validity $(n=2)[11,14]$, discriminant validity $(n=2)[11,13]$, convergent validity $(n=2)[11,14]$, construct validity $(n=2)[12,13]$, factorial validity $(n=2)[11$, 12], and 5-point scale qualitative feedback $(n=1)$ [6] were used in determining validity of the tools (Table 1). 
Table 1. Description of Health-based health survey validated in Brunei Darussalam

\begin{tabular}{|c|c|c|c|c|c|c|c|c|c|c|c|}
\hline Study & Year & Tool & & Purview & $\begin{array}{c}\text { Item } \\
\text { (n) }\end{array}$ & & $\begin{array}{l}\text { Sampling } \\
\text { Method }\end{array}$ & $\begin{array}{l}\text { Sample } \\
\text { (n) }\end{array}$ & Demography & $\begin{array}{c}\text { Procedure / Psychometric } \\
\text { test }\end{array}$ & Conclusion \\
\hline $\begin{array}{l}\text { Alhaji } \\
\text { et al } \\
{[11]}\end{array}$ & 2018 & $\begin{array}{l}\text { SF-36v2a } \\
\text { (Brunei- } \\
\text { Malay) }\end{array}$ & $\begin{array}{l}\text { (a) } \\
\text { (b) }\end{array}$ & $\begin{array}{l}\text { HQOL } \\
\text { Functional } \\
\text { status }\end{array}$ & 36 & $\begin{array}{l}\text { (a) } \\
\text { (b) }\end{array}$ & $\begin{array}{l}\text { Convenient } \\
\text { Random }\end{array}$ & 190 & $\begin{array}{l}\text { (a) General } \\
\text { population } \\
\text { (b) } \mathrm{CKD} \\
\text { patients } \\
\text { (c) Adults }\end{array}$ & $\begin{array}{l}\text { (a) Cross-cultural } \\
\text { adaptation } \\
\text { (b) Pretesting }(\mathrm{n}=20) \\
\text { (c) Reliability- } \\
\text { Cronbach's alpha, } \\
\text { (d) Validity_Face, } \\
\text { discriminant, } \\
\text { convergent, factorial } \\
\text { validity }\end{array}$ & $\begin{array}{l}\text { (a) The SF-36v2 is } \\
\text { reliable and valid in } \\
\text { Brunei } \\
\text { (b) The exact } \\
\text { hypothesized two- } \\
\text { summary scales were } \\
\text { not replicated in } \\
\text { Brunei and should be } \\
\text { interpreted with } \\
\text { caution } \\
\text { (c) Further evaluation } \\
\text { such as test-retest is } \\
\text { suggested }\end{array}$ \\
\hline $\begin{array}{l}\text { Talip } \\
\text { et al } \\
{[12]}\end{array}$ & 2017 & $\begin{array}{l}\text { M-SEQ-12b } \\
\text { (Brunei- } \\
\text { Malay) }\end{array}$ & (a) & $\begin{array}{l}\text { Smoking } \\
\text { refraining }\end{array}$ & 12 & (a) & Purposive & 40 & $\begin{array}{ll}\text { (a) } & \text { High } \\
& \text { school } \\
& \text { students } \\
\text { (b) } & 13-16 \\
& \text { years old }\end{array}$ & $\begin{array}{l}\text { (a) Forward/backward } \\
\text { translation } \\
\text { (b) Pretesting (n=5) } \\
\text { (c) Reliability- } \\
\text { Cronbach's alpha, test- } \\
\text { retest reliability (intra- } \\
\text { class coefficient, ICC) } \\
\text { (d) Validity-Construct, } \\
\text { factorial validity }\end{array}$ & $\begin{array}{l}\text { (a) The M-SEQ-12 is a } \\
\text { valid and reliable scale } \\
\text { for use in secondary } \\
\text { school students in } \\
\text { Brunei } \\
\text { (b) It has potential clinical } \\
\& \text { research application } \\
\text { (c) Further research on } \\
\text { concurrent validity of }\end{array}$ \\
\hline
\end{tabular}




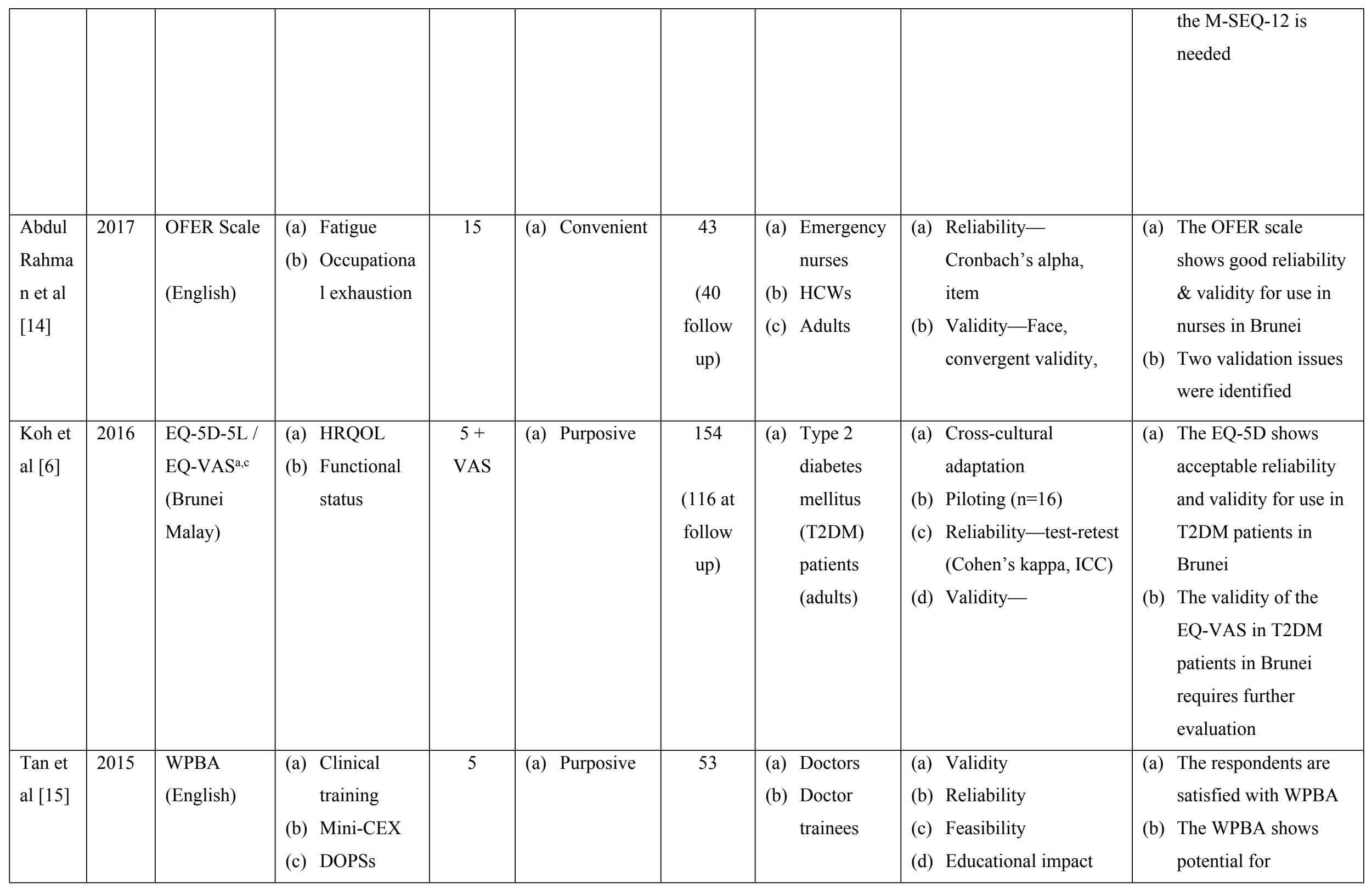




\begin{tabular}{|c|c|c|c|c|c|c|c|c|c|c|c|c|c|}
\hline & & & & $\begin{array}{l}\text { MSF } \\
\text { CBD }\end{array}$ & & & & & & (e) & Acceptability & & $\begin{array}{l}\text { integration in Asian } \\
\text { postgraduate training } \\
\text { programmes despite } \\
\text { systemic, cultural, and } \\
\text { language barriers. }\end{array}$ \\
\hline $\begin{array}{l}\text { Moha } \\
\text { mmed } \\
\text { et al } \\
{[13]}\end{array}$ & 2013 & $\begin{array}{l}\mathrm{CPQ}_{11-14} \\
\text { (Short- } \\
\text { Form) } \\
\text { (Brunei } \\
\text { Malay) }\end{array}$ & & $\begin{array}{l}\text { Oral- } \\
\text { HRQOL } \\
\text { Oral health }\end{array}$ & 18 & (b) Convenient & 457 & & $\begin{array}{l}\text { Primary } \\
\text { school } \\
\text { pupils } \\
11-14 \\
\text { years }\end{array}$ & $\begin{array}{l}\text { (f) } \\
\text { (g) } \\
\text { (h) } \\
\text { (i) }\end{array}$ & $\begin{array}{l}\text { Forward/backward } \\
\text { translation } \\
\text { Piloting (n=20) } \\
\text { Reliability_Cronbach } \\
\text { alpha, test-retest } \\
\text { reliability (ICC) } \\
\text { Validity_construct, } \\
\text { discriminant validity }\end{array}$ & 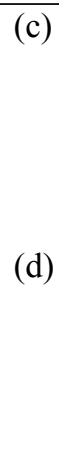 & $\begin{array}{l}\text { The CPQ11-14 } \\
\text { appears reliable for } \\
\text { use in Bruneian } \\
\text { children } \\
\text { Its clinical application } \\
\text { needs further } \\
\text { investigation }\end{array}$ \\
\hline
\end{tabular}

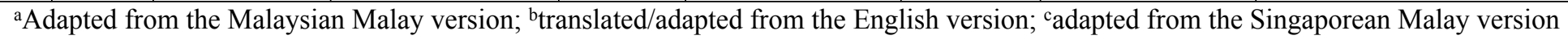

HCWs, Healthcare Workers; HRQOL, Health-Related Quality of Life; SF-36, Short Form Survey-36; M-SEQ-12, Modified Smoking Self-Efficiency Questionnaire; OFER, Occupational Fatigue Exhaustion Recovery Scale; EQ-5D-5L/VAS, EuroQol/Visual Analogue Scale; WPBA, Workplace-Based Assessment; $\mathrm{CPQ}_{11-14}$, Child Perception Questionnaire; Mini-CEX, Mini-Clinical Examination; DOPSs, Directly Observed Practical Skills; MSF, Multisource Feedback; CBD, Case-Based Discussion 


\section{Health-related Tools validated in Brunei Darussalam}

Three studies $[6,11,13]$ validated health-related quality of life (HRQOL) instruments. The SF-36v2 is a 36-item tool which measures generic HRQOL in 8 scales (physical functioning, rolephysical, bodily pain, general health, vitality, social functioning, role-emotional, and mental health). These 8 domains are reducible to two summary scales, physical component summary and mental component summary. The SF-36v2 was found valid and reliable for use in Brunei, among chronic kidney disease (CKD) patients and the general population [11].

The EQ-5D or EQ-5D-5L is a 5-item utility-based tool measures generic HRQOL under 5 dimensions (anxiety/depression, mobility, pain/discomfort, self-care, and usual activities) alongside a $20 \mathrm{~cm}$ vertical EQ-VAS with number scale between 0 and 100 [6]. The EQ-5D showed acceptable reliability and validity for use among Type 2 Diabetes Mellitus (T2DM) patients. The $\mathrm{CPQ}_{11-14}$ (short form) is an 18-item instrument variant for measuring oral-HRQOL in 5 broad domains (oral health and oral health-related well-being, oral symptoms, functional limitations, emotional well-being, and social well-being) [13]. The $\mathrm{CPQ}_{11-14}$ was found to be reliable for use among children in Brunei.

The other 3 health-based instruments validated in Brunei bordered on smoking refraining $(n=1),[12]$ occupational exhaustion and fatigue among healthcare workers (HCWs) $(n=1)$ [14], and workplace-based assessment of doctor trainees [15]. The m-SEQ-12 is a 12-item scale which measures one's capability to desist from smoking in two dimensions (internal and external stimuli) [12]. The m-SEQ-12 was found to be valid and reliable for use among secondary school students and have potential clinical and research application in Brunei Darussalam.

The OFER scale is a 15-item scale for measuring work-related fatigue under 3 domains (chronic fatigue, acute fatigue, and persistent fatigue) [14]. The OFER scale showed good reliability and validity for use among nurses in Brunei. The WPBA tools (Mini-Clinical Examination, Directly Observed Practical Skills, Multisource Feedback, and Case-Based Discussion) were evaluated among doctors and doctor trainees for "validity, reliability, feasibility, educational impact, and acceptability" [15]. The findings showed excellent satisfaction in all the 5 headings, thereby showing potential for integration in postgraduate medical training in Asia.

However, further investigations were suggested in the studies. Additional psychometric evaluation such as the test-retest validity test and caution in interpreting the two-dimensional summary scores 
of the SF-36v2 have been advised [11]. Other recommendations include concurrent validity test for m-SEQ-12 [12]; increased sample size and convergent validity test, by inference, for the OFER scale [14]; further validity tests on EQ-VAS in T2DM patients [6]; further investigation on clinical application of the $\mathrm{CPQ}_{11-14}[13]$; and systemic, cultural and language barrier concerns for the WPBA [15]. (Table 1)

\section{Discussions}

A lot of questionnaire-based studies in Brunei Darussalam either adapt existing questionnaires, often from Malaysia or used directly translated tools or self-developed questionnaires with little or no psychometric evaluation [7]. The use of non- or poorly-validated questionnaires affect data quality, outcomes and comparability of the finding with other similar findings.[2, 16]. Our review showed that Cronbach's alpha test was the most widely used test of reliability of quantitative tool validation in Brunei Darussalam, which is similar to what is obtainable globally [17]. However, its ubiquitous use has been criticized for being misunderstood and misapplied [18], thereby leading to the suggestion that Cronbach's alpha should be measured alongside other tests of reliability [19] such as the split-half [20].

The majority of the tools $(n=4)$ were validated in the Malay language and none in Chinese or other minority languages. Ethnic-wise, Brunei Darussalam is composed of Brunei Malay Brunei Malay (65.7\%), Chinese (10.3\%), and others (24.0\%) which comprised of the indigenous groups of the Malay race namely Belait, Bisaya, Brunei, Dusun, Kedayan, Murut and Tutong [21]. Although Malay is the lingua franca in Brunei Darussalam, the validations of survey tools in the other minority languages, especially Chinese language, are need needed, in line with the international best practice of survey tools cross-cultural adaptation [22].

Similarly, the majority of the health-based tools evaluated in Brunei Darussalam were validated on a homogenous sample rather than a heterogeneous sample, thereby making such tool inapplicable for certain population which were not covered in the validation [16]. For a tool to be applicable in a broad population, its whole psychometric scale length needs to be validated in a heterogeneous sample from a wide range of sociodemographic strata (e.g. a mix of the old and the young, sick and healthy, male and female) rather than in a homogeneous sample, as the latter lower variance and factor loading [23]. Further, the sample sizes for the psychometric evaluations of health-based tools in Brunei Darussalam were usually small. The minimum sample size 
recommended for factor analysis, an important validity test, was 300 participants [23, 24]. The highest sample size for health-based validation in Brunei Darussalam was 457 participants [13].

This was often not the case for other psychometric evaluations of non-health-based tools validated in Brunei Darussalam. Example, the My Class Inventory (MCI) tool for assessing 'students' perceptions of the classroom learning environment $(n=1565)$ [25], the What Is Happening In This Class (WIHIC) for measuring 'perceptions of learning environment' ( $\mathrm{n}=644)$ [26], the Students' Perception of Assessment Questionnaire (SPAQ) for measuring students perception of assessment ( $\mathrm{n}=1028)$ among secondary school students [27], the Questionnaire on Teacher Interaction (QTI) for evaluating 'students' Enjoyment of their Sciences Lessons (ENJ)' among students among primary school pupils $(n=3104)$ [28], and the Cultural Learning Environment Questionnaire (CLEQ) for evaluating 'culturally-sensitive' factors in teacher trainees learning environments' among trainee teachers $(n=475)$ [29].

Three other non-health validations in Brunei Darussalam with low sample size included the Eysenck Personality Questionnaire-Revised (EPQ-R) Short Scale for measuring personality traits among trainee teachers $(n=223)$ [30], the 'MODEL (Meanings, Organise, Develop, Execute, Link)', a local framework, for 'exploring students' cognitive competency in solving non-routine problems' among junior college students $(n=167)$ [31], and the Minnesota Multiphasic Personality Inventory-Revised (MMPI-2) for assessing personality traits among student teachers $(n=84)$ [7]. Although fewer than 100 participants have been used to psychometrically evaluate a tool,[32] a sample size of 100 and below is considered 'poor sampling' [24]. The use of convenience sampling method has also been considered a limitation for generalizability [16].

Finally, our scoping review of health-based instruments validated in Brunei Darussalam highlights the paucity of published psychometric evaluation of health-based tools, the use of small and homogenous sample sizes, the lack of diversity in the language of the tools, and the absence of diversity of psychometric tests used in the validation processes. We, therefore, recommend that health and medical researchers in Brunei Darussalam to endeavour to validate and publish the questionnaires they adopt or self-develop before use in research. Importantly, the psychometrically evaluation of the tools should aim to include large heterogeneous participants and the languages should be diversified to include other languages such as the Chinese language. Similarly, varied sampling strategies and psychometric tests should be used for survey tool validations. 


\section{References}

1. Alhaji MM, Tan J, Hamid MR, Timbuak J, Naing L, Tuah NA. Determinants of Quality of Life as Measured by Variants of SF-36 in Patients with Predialysis Chronic Kidney Disease. Saudi Med J. 2018;39(7):653-61.

2. Bolarinwa O. Principles and methods of validity and reliability testing of questionnaires used in social and health science researches. Niger Postgrad Med J . 2015;22(4):195.

3. Bullinger M, Alfonso J, Apolone G, Leplege M, Sullivan M W-DS. Translating Health Status Questionnaires and Evaluating Their Quality: The IQOLA Project Approach. J Clin Epidemiol . 1998;51(11):913-23.

4. Mbada CE, Adeogun GA, Ogunlana MO, Adedoyin RA, Akinsulore A, Awotidebe TO, et al. Translation, cross-cultural adaptation and psychometric evaluation of yoruba version of the short-form 36 health survey. Health Qual Life Outcomes . 2015;13(1):141.

5. Suzukamo Y, Fukuhara S, Green J, Kosinski M, Gandek B, Ware JE. Validation testing of a three-component model of Short Form-36 scores. J Clin Epidemiol. 2011;64(3):301-8.

6. Koh D, Abdullah AMK Bin, Wang P, Lin N, Luo N. Validation of Brunei's Malay EQ-5D questionnaire in patients with type 2 diabetes. PLoS One . 2016;11(11):1-9.

7. Mundia L. Social desirability, non-response bias and reliability in a long self-report measure: Illustrations from the MMPI-2 administered to Brunei student teachers. Educ Psychol . 2011;31(2):207-24.

8. Peters MDJ, Godfrey CM, Khalil H, McInerney P, Parker D, Soares CB. Guidance for conducting systematic scoping reviews. Int J Evid Based Healthc. 2015;13(3):141-6.

9. WHO. Constitution of WHO: principles . WHO. World Health Organization; 1948 [cited 2018 May 21]. Available from: http://www.who.int/about/mission/en/

10. Moher D, Liberati A, Tetzlaff J, Altman DG, Altman D, Antes G, et al. Preferred reporting items for systematic reviews and meta-analyses: The PRISMA statement . Vol. 6, PLoS Medicine. 2009. p. e1000097.

11. Alhaji MM, Johan NH, Sharbini S, Abdul Hamid MR, Khalil M, Tan J ackson, et al. 
Psychometric Evaluation of the Brunei-Malay SF-36 version 2 Health Survey. Asian

Pacific J Cancer Prev. 2018;19(7). Available from:

http://journal.waocp.org/article_64831.html

12. Talip T, Kifli N, Naing L. Reliability and Validity of the Malay Version of a Modified Smoking Self-Efficacy Questionnaire among Bruneian Secondary Students. Asian Pacific J Cancer Prev Asian Pac J Cancer Prev. 2017;18(186):1499-505.

13. Mohammed A, Thomson W, Foster Page L. Validation of a Malay version of the shortform Child Perceptions Questionnaire (CPQ11-14) in Brunei. Brunei Darussalam J Health. 2013;56-69.

14. Rahman HA, Naing L, Mumin K. VALIDATION OF THE OCCUPATIONAL FATIGUE EXHAUSTION RECOVERY(OFER) SCALE AMONG EMERGENCY NURSES IN ABRUNEI PUBLIC HOSPITAL. 2017;8(3):50-5.

15. Tan J, Tengah C, Chong VH, Liew A, Naing L. Workplace Based Assessment in an Asian Context: Trainees' and Trainers' Perception of Validity, Reliability, Feasibility, Acceptability, and Educational Impact. J Biomed Educ . 2015;2015:1-8.

16. Morgado FFR, Meireles JFF, Neves CM, Amaral ACS, Ferreira MEC. Scale development: Ten main limitations and recommendations to improve future research practices. Psicol Reflex e Crit . 2017;30(1):1-20.

17. Tavakol M, Dennick R. Making sense of Cronbach’s alpha. Int J Med Educ . 2011;2:53-5.

18. Cho E, Kim S. Cronbach's Coefficient Alpha. Organ Res Methods. 2015;18(2):207-30.

19. Cho E. Making reliability reliable: a systematic approach to reliability coefficients. Organ Res Methods. 2016;19(Cho):1-81.

20. Mundia L. Assessment of GenNEXT learning outcomes at the University of Brunei Darussalam: a qualitative review of selected opportunities, benefits and challenges in human resource development. J Int Educ Leadersh . 2012;2(3):1-21.

21. Brunei Ministry of Health. Health Information Booklet 2016. 2016; Available from: http://www.moh.gov.bn/Downloadables/Health Information Booklet 2016 (21st Edition 
Revision 2).

22. Keller SD, Ware JE, Bentler PM, Aaronson NK, Alonso J, Apolone G, et al. Use of structural equation modeling to test the construct validity of the SF-36 Health Survey in ten countries: Results from the IQOLA Project. J Clin Epidemiol. 1998;51(11):1179-88.

23. Gie Yong A, Pearce S. A Beginner's Guide to Factor Analysis: Focusing on Exploratory Factor Analysis. Tutor Quant Methods Psychol . 2013;9(2):79-94.

24. Williams B, Onsman A, Brown T. Exploratory factor analysis: A five-step guide for novices. J Emerg Prim Heal Care. 1996;19(May):42-50.

25. Majeed A, Fraser BJ, Aldridge JM. Learning environment and its association with student satisfaction among mathematics students in Brunei Darussalam. Learn Environ Res . $2002 ; 5(2): 203-226$.

26. Hunus R, Fraser B. Chemistry Learning Environment in Brunei Darussalam's Secondary Schools. In: Fisher D, Rickard T, editors. Science, Mathematics and Technology Education and National Development. Hannoi: Vietnam: Proceedings of the Vietnam Conference; 1997. p. 108-20.

27. Dhindsa HS, Omar K, Waldrip B. Upper secondary Bruneian science students' perceptions of assessment. Int J Sci Educ. 2007;29(10):1261-80.

28. Goh SC, Fraser BJ. Validation of an Elementary School Version of the Questionnaire on Teacher Interaction. Psychol Rep . 1996;79(2):515-22.

29. Dhindsa HS, Fraser BJ. Culturally-Sensitive Factors in Teacher Trainees' Learning Environments. Learn Environ Res. 2004;7(2):165-81.

30. Mundia L, Bakar HAZBA. The suitability of the EPQ-R Short Scale for counselling Brunei student teachers when administered in English and Malay languages. Comp A J Comp Int Educ . 2010;40(5):641-58.

31. Chong MSF, Shahrill M. The use of an emerging framework to explore students' cognitive competency. Indian J Sci Technol. 2016;9(16).

32. Sapnas KG, Zeller RA. Minimizing sample size when using exploratory factor analysis for 
bioRxiv preprint doi: https://doi.org/10.1101/383547; this version posted Auqust 2, 2018. The copyright holder for this preprint (which was not certified by peer review) is the author/funder, who has granted bioRxiv a license to display the preprint in perpetuity. It is made available under aCC-BY 4.0 International license.

measurement. J Nurs Meas. 2002;10(2):135-54. 